\title{
Clinical presentation of tubal ectopic pregnancy
}

\author{
Kavitha Garikapati*, M. Parvathi Devi, N. Alekya Goud
}

Department of Obstetrics and Gynecology, Dr. PSIMS and RF, Gannavaram, Andhra Pradesh, India

Received: 31 December 2019

Accepted: 29 January 2020

\section{*Correspondence:}

Dr. Kavitha Garikapati,

E-mail: kavithagarikapati4@gmail.com

Copyright: () the author(s), publisher and licensee Medip Academy. This is an open-access article distributed under the terms of the Creative Commons Attribution Non-Commercial License, which permits unrestricted non-commercial use, distribution, and reproduction in any medium, provided the original work is properly cited.

\section{ABSTRACT}

Background: When the fertilized ovum gets implanted at site other than normal position of uterine cavity, it is known as ectopic pregnancy. Incidence of ectopic pregnancy is $1-2 \%$ of all reported pregnancies. It is an unmitigated disaster of human production and the most important cause of morbidity and mortality in first trimester with major cause of reduced child bearing potential. It is notorious in its clinical presentation, challenging the attending physician.

Methods: women with risk factors, signs and symptoms and with confirmed diagnosis. Women discharged against medical advice. Study population is 50. Retrospective analysis for 3 years (2016-2019). Objectives of this study were to study the incidence, risk factors, clinical presentation, diagnosis and changing trends of modern management. Results analysed after entering the information in the excel sheets using descriptive analysis

Results: Out of 4940 deliveries, 50 were tubal ectopic pregnancies $1.012 \%$. Women aged 20-25 years were $52 \%$. In our study, multiparous were $68 \%$. Common symptoms were abdominal pain $80.2 \%$, amenorrhea $72 \%$, urine gravindex test positive $92.8 \%$. Etiology was PID 20\%, previous ectopic pregnancy 4\%, IUCD 4\%, LSCS with tubectomy $16 \%$, most common site is ampulla $82 \%$. About $78 \%$ were ruptured. Tubal abortions $4 \%$, salpingectomy done in $82 \%$. Laparotomy in $2.43 \%$ in hemodynamically unstable. Medical management $8 \%$. Salpingostomy in $4 \%$ and expectant management $2 \%$. Morbidity in the form of blood transfusion $23.48 \%$, DIC with ICU admission $2 \%$. No mortality.

Conclusions: A high index of clinical suspicion with underlying risk factors may get us early diagnosis for timely intervention.

Keywords: Risk factors, Salpingectomy, Tubal ectopic pregnancy

\section{INTRODUCTION}

When fertilized ovum gets implanted at site other than normal position of uterine cavity, it is known as ectopic pregnancy. Ectopic gestation is an unmitigated disaster of human production and is the most important cause of morbidity and mortality in first trimester with major cause of reduced child bearing potential. $95-98 \%$ of all ectopic pregnancies are seen in fallopian tubes. ${ }^{1}$

It is the most important cause of maternal mortality and morbidity in first trimester. ${ }^{2}$
Diagnosis requires a high index of suspicion as the classic triad of amenorrhea, abdominal pain and vaginal bleeding is not seen in majority of cases. Women may present with nonspecific symptoms, unaware of ongoing pregnancy or may even present with hemodynamic shock. The contribution of ectopic pregnancy to maternal mortality in developing countries including India is not presently known, with data from few studies indicating $3.5-7.1 \%$ maternal deaths due to ectopic pregnancy. 3,4

Risk factors like previous ectopic pregnancy, tubal sterilization, tubal corrective surgeries, infertility, tubal 
pathology, PID, prior abortions, assisted reproductive technologies, IUD, multiple sexual partners, prior abdominal or pelvic surgeries have been implicated in the development of ectopic pregnancy. ${ }^{5}$ Incidence of ectopic pregnancy is $1-2 \%$ of all reported pregnancies. The risk of death from ectopic pregnancy has declined by $90 \% .{ }^{6} \mathrm{~A}$ knowledge of associated risk factors helps identify women at higher risk in order to facilitate early and more accurate diagnosis. ${ }^{7}$ Chlamydia trachomatis has been linked to $30-50 \%$ of all ectopic pregnancies. ${ }^{8}$ Because of the variety of symptoms that may occur, ectopic pregnancy has been called "the great Masquerader". The classical clinical triad is seen in less than $50 \%$ of cases. ${ }^{9}$

The study by Gaskins et al, reminds us that while STI'S contribute to a major cause of ectopic pregnancies, there is a strong evidence both epidemiological and experimental that ectopic pregnancy is associated with other risk factors and may occur with apparently normal fallopian tubes. ${ }^{10}$

\section{METHODS}

This study was conducted in the department of obstetrics and gynecology, Dr. Pinnamaneni Siddhartha Institute of Medical Sciences and Research Foundation, Chinoutpalli, Andhra Pradesh, India. During the period of August 2016 to July 2019 for a period of 3 years.

\section{Inclusion criteria}

- Women with risk factors, signs and symptoms and women with confirmed diagnosis.

\section{Exclusion criteria}

- Women who got discharged against medical advice. Study population were 50 .

Retrospective descriptive analysis. Objectives of this study were to study the incidence, risk factors, clinical presentation. Diagnostic methods and changing trends in modern management. The case sheet of patients diagnosed with tubal ectopic pregnancies were traced through labour ward, emergency ward registers, medical records departments and operation theatre registers.

Information regarding the total number of tubal ectopic pregnancies in the study period. details of age, socio economic status, parity, clinical symptoms and signs, risk factors, diagnostic tools used, previous $\mathrm{H} / \mathrm{O}$ ectopic pregnancy, any pelvic surgeries, tubal correction surgeries, associated morbidity and mortality were obtained.

\section{RESULTS}

During the study period of three years, there were 4940 deliveries and 50 cases were diagnosed as tubal ectopic pregnancies giving the incidence of $1.01 \%$.

Table 1: Age.

\begin{tabular}{|lll|}
\hline Age (years) & Number & Percentage \% \\
\hline$<20$ & 6 & 12 \\
\hline $20-25$ & 26 & 52 \\
\hline $26-30$ & 8 & 16 \\
\hline$>30$ & 10 & 20 \\
\hline
\end{tabular}

Majority of patients belonged to 20-25 years age group $52 \%$ (Table 1).

Table 2: Gravidity.

\begin{tabular}{|ll|l|}
\hline Primi & Number $\mathbf{1 6}$ & \% 32 \\
\hline G2 & 12 & 12 \\
\hline G3 & 20 & 20 \\
\hline$\geq$ G4 & 2 & 2 \\
\hline
\end{tabular}

In the present study, $68 \%$ were multigravida (Table 2).

Table 3: Risk factors.

\begin{tabular}{|lll|}
\hline Risk factors & Number & $\%$ \\
\hline H/O PID & 10 & 20 \\
\hline H/O previous ectopic pregnancy & 2 & 4 \\
\hline H/O previous tubectomy & 20 & 40 \\
\hline Post LSCS & 15 & - \\
\hline Vaginal delivery & 5 & - \\
\hline H/O IUCD & 2 & 4 \\
\hline H/O ART & 1 & 2 \\
\hline Post LSCS & 12 & 24 \\
\hline H/O induced abortion & 2 & 4 \\
\hline
\end{tabular}

A total $20 \%$ had $\mathrm{H} / \mathrm{O}$ pelvic infection, $4 \%$ had previous ectopic, post tubectomy in 40\%, IUCD $4 \%$ (Table 3 ).

Table 4: TVS findings.

\begin{tabular}{|lllll|}
\hline Adnexal mass & hemoperitoneum & Provisional diagnosis & No. of patients & $\%$ \\
\hline Present & Moderate to massive & Ruptured ectopic & 39 & 78 \\
\hline No mass & Moderate & Tubal abortion & 3 & 6 \\
\hline Well defined sac & No & Unruptured ectopic & 4 & 8 \\
\hline Mass seen & minimal & Unruptured tubal ectopic & 3 & 6 \\
\hline No mass & Nil & PUL, Follow up & 1 & 2 \\
\hline
\end{tabular}




\section{Clinical presentation}

In the present study, $80.2 \%$ had abdominal pain, followed by $\mathrm{H} / \mathrm{O}$ amenorrhoea $72 \%, \mathrm{H} / \mathrm{O}$ bleeding or spotting per vaginum in $65.4 \%$, UPT was positive in $80 \%$ of cases, weakly positive in $20 \%$ of cases.

Ultrasound abdomen along with transvaginal USG diagnosis of adnexal mass with hemoperitoneum in $78 \%$ suggestive of ruptured tubal ectopic, out of which $75 \%$ of patients presented with shock. In $6 \%$, no adnexal mass but free fluid in peritoneum seen. In $3 \%$ of cases, adnexal mass with minimal free fluid seen with ring of fire sign. In $2 \%$ cases no mass is seen in scan, no hemoperitoneum but due to weak positive UPT and significant serum $\beta$ hcg values patient had been follow up (Table 4).

A total $82 \%$ ectopics were seen in ampullary region (Table 6).

Table 5: Management.

\begin{tabular}{|ll|}
\hline Diagnosis & Procedure \\
\hline Ruptured tubal ectopic & $\begin{array}{l}\text { Laparoscopic salpingectomy in stable patents, salpingectomy by laparotomy } \\
\text { in unstable }\end{array}$ \\
\hline $\begin{array}{l}\text { Unruptured tubal ectopic with } \\
\text { hemoperitoneum }\end{array}$ & Salpingostomy \\
\hline Unruptured with no hemoperitoneum & Medical management \\
\hline Tubal abortion & Laparotomy, hemoperitoneum drained \\
\hline PUL & $\begin{array}{l}\text { Expectant management with Sr. } \beta \text { hcg follow-up and TVS after } 5 \text { days } \\
\text { showed heterogenous mass in left adnexa. So, Lap. Salpinectomy was done }\end{array}$ \\
\hline
\end{tabular}

Morbidity in the form of blood and blood products transfusion, ICU admission with DIC, prolonged hospital stay, wound infection was noted. No maternal mortality is seen in our study.

Table 6: Site of tubal ectopic.

\begin{tabular}{|lll|}
\hline Site of ectopic & Number & $\%$ \\
\hline Ampulle & 41 & 82 \\
\hline Cornual & 8 & 16 \\
\hline Isthmus & 1 & 2 \\
\hline Fimbrial & None & None \\
\hline
\end{tabular}

\section{DISCUSSION}

The incidence of ectopic pregnancy has been on rise past 20 years. The incidence in this present study was $1.01 \%$

Majority of woman, (68\%) in our study group belonged to the age group of 20-30 years, which is close to the studies done by Mulfti S, et al (75.4\%) Panchal D, et al $(71.66 \%)$ and Rashmi. ${ }^{11,12}$ Urine pregnancy test was positive in $92.8 \%$. In this study which correlated with study done by Gaddagi RA et al $(97.3 \%){ }^{13}$

In the present study group, majority of women with ectopic pregnancy were multi gravida (68\%) which correlates with the studies done by Shetty K, et al (83.9\%) Panchal D et al, (81.66\%) and Poonam et al, $(83.6 \%) .^{12,14,15}$

The higher incidence in multigravida is probably due to previous miscarriages and infection resulting in tubal damage.
In the present study group history of pelvic inflammatory disease was present in $20 \%$ of the cases which is correlating with the study done by Bhavna et al, $22.7 \%$ of the cases with ectopic pregnancy. ${ }^{16}$

In this study group, $6 \%$ of the women were infertile which is correlating with the studies done by Panchal D, et al, (11.66\%) and Mufti $\mathrm{S}$ et al, (8.77\%). ${ }^{11,12}$ Pelvic infection is the predisposing factor for tubal damage and infertility leading to ectopic pregnancy. In this study $4 \%$ of the women had history of previous ectopic pregnancy which is correlating with the studies done by Mulfti S et al, $(5.26 \%)$ and Shabab U et al, (5\%). ${ }^{11,17}$ The pathology is being underlying tubal pathology which is almost always bilateral.

In this study $40 \%$ cases had history of tubal sterilization with post LSCS and normal vaginal delivery of which $6 \%$ had tubal ectopic with puerperal sterilization which correlates with the studies done by Uzmashabab et al, $(5 \%)$ and Shrestha et al, (5\%). ${ }^{17,18}$ Improper surgical technique and formation of peritubal fistulas may result in ectopic pregnancy. In postpartum period, edematous, congested and friable tube increases the chance of incomplete tubal occlusion resulting in ectopic implantation.

Ectopic pregnancy with IUCD in situ accounted for $4 \%$ which correlates with the studies done by Shetty KS et al, (6.4\%) Shrestha et al, (5\%) and Fageeh WM $(5.8 \%) .{ }^{14,18,19}$ The risk of tubal pregnancy is more if a woman conceives with IUCD in situ.

The triad of investigations for diagnosis are urine gravindex test, serum $\beta \mathrm{hCG}$ and transvaginal 
ultrasonogram. Serum $\beta$ hCG levels to be followed up where the diagnosis is uncertain and when USG is inconclusive in early gestation. ${ }^{20}$

However, ultrasonogram must be the initial investigation of choice in symptomatic women.

The triad of presenting complaints were abdominal pain followed by amenorrhea and abnormal vaginal bleeding. Clinical signs included abdominal tenderness, adnexal tenderness and cervical motion tenderness.

The commonest site of tubal ectopic was the ampulla. Ampullary part is the most commonly involved in most of the studies on ectopic pregnancy. ${ }^{21}$ Right side tubal ectopic is seen in $60 \%$ and left tubal ectopic pregnancy in $40 \%$ cases consistent with other studies. ${ }^{22}$

Ruptured ectopic pregnancy present in $78 \%$, unruptured in $14 \%$ and tubal abortion $6 \%$.

Laparoscopy and medical therapy are now the widely used therapeutic modalities with great success.

But as medical management needs close follow up and hospitalization for observation, surgical management is still the choice in India. ${ }^{23}$

Patients may have short-hospital stay, reduced morbidity and more so conservation of fertility. ${ }^{24}$ However choice depends on diagnosis at early gestational age and stable condition of patients. ${ }^{25}$

In this study morbidity included anaemia, blood and blood products transfusion, ICU admission with DIC, wound infection, prolonged hospital stay for 1 patient.

So, one should have a high index of suspicion in detecting, evaluating risk factors, diagnosing at the earliest so that fertility potential is preserved with reduced morbidity. ${ }^{26}$ No maternal mortality found in this study. Consistent with Abbas A and Akram H study. ${ }^{27}$

\section{CONCLUSION}

As the incidence of ectopic pregnancy is on rise with its notorious presentation, a high index of clinical suspicion with early diagnosis using transvaginal USG, Sr $\beta$ hCG may help to diagnose at the earliest and reduce the morbidity and the fertility potential may also be preserved by medical conservative management.

\section{ACKNOWLEDGMENTS}

Authors would like to acknowledge HOD, department of obstetrics and gynecology, Dr. PSIMS and RF and medical superintendent for allowing to do this study and thank all the medical and paramedical staff and departmental stenographer who have helped me complete this study.
Funding: No funding sources

Conflict of interest: None declared

Ethical approval: The study was approved by the Institutional Ethics Committee

\section{REFERENCES}

1. Surette AM, Dunham SM. Early pregnancy risks. In:AH De Cherney et al., eds. Current Diagnosis and Treatment Obstetrics and Gynecology. $11^{\text {th }}$ ed. New York: Mc Graw Hill; 2013:234-249.

2. Mahhoob U, Masher SH. Management of ectopic pregnancy, a two-year study. I Ayub Meb Coll Abbotthad. 2006;18(4):34-7.

3. Shah P, Shah S, Kutty RV, Modi D. Changing epidemiology of maternal mortality in rural India: time to reset strategies for MDG-5. Trop Med Int Health. 2014;19(5):568-7.

4. Yadav K, Namdeo A, Bhargava M. A retrospective and prospective study of maternal mortality in a rural tertiary care hospital of Central India. Indian J Community Health. 2013;25(1):16-21.

5. Cumminghum FG, Leveno, Bloon St, Hauth JC, Rouse DJ, Spong CY. Ectopic pregnancy; In Williams obstetrics, $23^{\text {rd }}$ United States of America MC Graw Hills Publishing; 2010:238-254.

6. Shetty VH, Some Gowda LM. Role of ultrasonography in diagnosis of ectopic pregnancy with clinical analysis and management in tertiary care hospital. J Obstet Gynaecol India. 2014;64(5):354.

7. Karaer A, Avsar FA, Batioglu S. Risk factors for ectopic pregnancy a case-control study. Aust NZ Obstet Gynaecol. 2006:46:521-7.

8. Turner C, Horner P. British Fertility Society Guidelines for practice. Hum Fertil (Camb). 2010;13:115-25.

9. Arora R, Rathore AM, Habeebullah S, Oumachigui A. Ectopic pregnancy changing trends. JIMA. 1998;96:53-7.

10. Gaskins AJ, Missmer SA, Rich-Edwards JW, Williams PL, Souter I, Chavuro JE. Demographic, lifestyle and reproductive risk factors for ectopic pregnancy. Fert Steril. 2018;110:1328-37.

11. Shagufta SM, Samina M, Reyaz AR, Wasiqa K. Ectopic pregnancy; an analysis of 114 cases. JKPractitioner. 2012;17(4):20-3.

12. Panchal D, Vasihanavi G, Solanki K. Study of anagement inpatient with Ectopic pregnancy. Nat J Integ Res Med. 2011;2(3):91-4.

13. Gaddagi RA, Chandrashekbar AP. A clinical study of ectopic pregnancy. J Clin Diag Res. 2012;6:867-9.

14. Shetty S, Shetty A. A clinical study of ecoptic pregnancies in a tertiary care hospital of Mangalore, India. Innovat J Med Health Sci. 2014;4(1):305-9.

15. Poonam Y, Uprety D, Banerjee B. Ectopic Pregnancy- two years review from BPKHIS, Nepal. Kathmandu Uni. Med J. 2005;3:365-9.

16. Gupta BK, Pathania BK, Jindal M, Vohra R, Ahmed M. Risk factors for ectopic pregnancy; a case control 
study in tertiary care centre. J Dent Med Sci. 2014;13(3):23-7.

17. Shabab U, Hasmi HA. Different pattern of presentation of ectopic pregnancy and its management. J Surg Pak. 2013;18:1.

18. Shrestha J, Saha R. Comparison of lapoarscopy and laparotomy in the surgical management of ecotopic pregnancy. J Coll Phys Surgpak. 2012;22:760-4.

19. Fageeh WM. Diagnosis and management of ecotopic pregnancy in king Abdul Aziz University Hosptial, a four year experience. Med Sci. 2008:15:2.

20. Murray $H$, Baakdah $H$, Bardell $T$, Tuland $T$. Diagnosis and treatment of ectopic pregnancy. CMAJ. 2005;173(8):905-12.

21. Swenda TZ, Jogo AA. Ruptured tubal pregnancy in Makurid, North Central Nigaria. Niger J Med. 2008;17(1):75-7.

22. Udigwe GO, Umeonoihu OS, Mbachu II. Ectopic pregnancy: A 5-year review of cases at Nnamdikazikiwe University Teaching Hospital (NAUPTH) ZNEWI. NMJ. 2010:51:160-3.

23. Chatterjee S, Dey S, Chowdhury RG, Ganguli D. Ectopic pregnancy in previously infertile women pregnancy in previously outcome after laparaoscoptic management. Al Amen J Med Sck. 2009;2(1):67-72.

24. Jurkovie D, Ectopic pregnancy, IN: Edmonds DK, Editor, Dew Hurst textbook of obstetrics and Gynecology $7^{\text {th }}$ ed, USA: Blackwell Publishers; 2007.

25. Shah N, Khan NH. Ectopic pregnancy, presentation and risk factors, J Coll Physcians Surg Pak. 2005:15:535-8.

26. Majhi AK, Roy N, Karmakar KS, Banerjee PK. Ectopic pregnancy - An analysis of 180 cases. J Indian Med Assoc. 2007:105(6):310-2.

27. Abbas A, Akram H. Ecotopic pregnancy: Audit at Maula Bakhsh Teaching Hospital Sargodha. Prof Med J. 2011;18(1):24-7.

Cite this article as: Garikapati K, Devi MP, Goud NA. Clinical presentation of tubal ectopic pregnancy. Int J Reprod Contracept Obstet Gynecol 2020;9:1148-52. 